2nd International Conference Art, Illustration and Visual Culture in Infant and Primary Education

\title{
Design and illustration. Two of a kind
}

Henrique Cayatte Keynote SpeakerW

Cayatte, Henrique; (2012) "Design and Illustration. Two of a kind", p. 14-18 . In: Barbosa, Helena; Quental, Joana [Eds]. Proceedings of the 2nd International Conference of Art, Illustration and Visual Culture in Infant and Primary Education. São Paulo: Blucher, 2015. ISSN 2318-695X, ISBN: 978-989-98185-0-7

DOI 10.5151/edupro-aivcipe-O4

"One eye sees, the other feels" Paul Klee

Some fields " alk" to each other. Like eyes do.

Painting and drawing, architecture and engineering, maths and chemistry or design and illustration.

Like the left eye and the right eye.

When these fields a e together they are two faces of the same coin butalways slipping from one side to another trying to cooperate in the same adventure for the drawing: to fill a age together with letters and empty areas.

Design and illustration merge with a single purpose: to built a storytelling.

Contemporary architecture talks of "emptiness" when it want to study the relationship between buildings, squares, gardens, streets and empty spots perceived by walkers that randomly are finding $n$ w places, new volumes, new lights and new sensations.

If we change the word "art" by "illustration" and "painting" by "drawing" we can easily borrow and adapt the sentence of the great painter Frank Stella when he writes "after all, the aim of art is to create space (S) within wich the subjects of painting can live".

Our eyes, both, when reading a book, are those walkers searching for a tale, for letters, illustration, emptiness or, most often, a safe trip do their own childhood.

Silent or noisy walkers. Young or old, male or female from different geographies and cultures.

They search for meaning or simple adventure.

That's why design and illustration, when effectively are side by side, two of a kind, in a rich dialog, are so powerful.

Why? Why this passion?

Let's try to discover it together.

\section{First things first.}

People loves storytelling.

During centuries this was, and remains, an oral tradition.

It was the only way of handing over the culture of a community. Amongst olders and youngsters storytelling was a praised ritual.

Oral tradition has always talked about nature, family, neighbors, animals but also about the fantastic, the unknown, thoughts or traditions. Near but not together with this words we could discover primitive drawings and paintings. 
$2^{\text {nd }}$ International Conference Art, Illustration and Visual Culture in Infant and Primary Education
' Congresso Internacional

de Arte, Ilustração e Cultura Visual

na Educação Infantil e Primária

Words and drawings lived apart in spite of standing side by side.

Before the start of writing we had the illustration and drawing, with its specific o ganization in the form of pictograms, were we found a common ground in many different cultures and civilizations. Unable to retain abstract thinking next step was the ideographic writing, like the chinese, cuneiform or hieroglyphs with their so well designed symbols.

Hieroglyphs were so complex that only with the amazing discover of the Rosetta Stone by Champollion, in 1822, we were able to understand the richness of this alphabet, composed of twenty-three symbols with a melting pot of pictograms, ideograms and phonetic elements among other elements thatallowed its democratization but however restricted to a power elite. In all of them drawing occupies the central role together with progressively phonetic element that gave us the space and time dimension as Ladislas Mandel refers in his fantastic book of 1998 "Écritures, Mirroir et des hommes et des sociétés".

"Dreams are illustrations from the book your soul is writing about you" Marsha Norman

This quote from the playwright "Night Mother", that won the Pulitzer Prize in 1983, drives us from utility to dream. And from dream to information was a small step.

When IKEA, today, is studying the possibility of providing the instructions, printed on paper, for installation of equipment with no text and only with illustrations together with numbers that help the clients to understand the sequence of the assemblage, shows the importance of this discipline.

This is the recognition of the universal nature of the illustration which its everywhere.

Sentences, as we have some in Portugal, like "if you don't read just see the drawings" or "if you do not understand I can draw you a picture" are, more or less, universal.

They show that illustration is here to stay won wings, $\mathrm{fl}$ w and often can avoid translation.

First to support autonomous narratives and then with a well deserved autonomy.

Today we can find it in all domains: ad ertising, pictograms, books, tv, internet and now in e-books.

But it was a long and rich history since those early times until this revolutionary XXI st century.

The illustration had to go through the woodcut, the incunable, with the beautiful paintings of the illuminated handwritten manuscripts, the stone sculptures in both facades and interior of churches, to serve religious allegories in stained glass or even in commercial and military insignia that went through centuries to reach a special moment with Gutenberg's movable type.

With Gutenberg everything changed. His experience was an essay of the democratization of knowledge. Since then, the role of illustration printed in a book, which made a long voyage from the roll of papyrus to the "codex" - paged book on sheets of parchment -, didn't changed.

Scientific illust ation, information illustration, infographics or together with literary narratives, illustration has the $\mathrm{fl}$ xibility to be used in all medias, showing its power to communicate and the talent of illustrators across all cultures and different cultural, religious and political realities.

But this path wasn't easy specially in the fi st decades of the XIXth century with the birth of photography.

"Photography is a reality so subtle that it becomes more real than reality." Alfred Stieglitz

Drawing, like painting, had already faced a huge problem: the representation of reality. Impressionism had already drawn a borderline between the role of pure representation and the possibility to introduce what was the "reading" of the reality by the artist even if this exercice would cause, often, a misunderstanding of the subject for the viewer.

Picasso, Bracque and Gris would complete this picture with cubism.

It was a turning point. 
$2^{\text {nd }}$ International Conference Art. Illustration and Visual Culture in Infant and Primary Education de Arte, llustracão e Cultura Visual

na Educação Infantil e Primária

Drawing and illustration, cartoon and collage could maintain their path because their codes were always clear: storytelling with pictures. About everything.

With the birth of photography the threat to drawing and illustration was strong.

Many predicted the end of drawing and painting. Because photo brought us, in a fi st moment, what we saw free of personal views. The tangible reality. It was a time before the personal viewsSof photographers! When they became "artists" like illustrators, painters or sculptors.

The viewer got reality in black and white against the color already living in the illustration. Different worlds that the future would combine many times. There were almost two hundred years of challenges and confrontations but also associations with advantages for both parties. Different poetics and techniques yet with so much affinitie

Illustration and photography were, and still are, partners in the information. Side by side in their respective fields, or simul aneously as in manipulation. It all started with the an handmade drawing "upon" the photographic image, using pencil or brush, which is now replaced by computer-generated drawing. Today we watch a total merging between illustration with the real image. This association, when used with deadly purpose, mixing deception and reality, eventually creates a sense of hyper-reality where is difficult to perceive what is true from what is false.

"Quantity produces quality. If you only write a few things, you're doomed." Ray Bradbur

Illustration is a matter of talent.

Talent to read previous to illustrate and to study different angles.

The fi st reading of a new text is always strange to our eyes. Sometimes because we don't know the work of the writer or because the text doesn't belong to the "family" we are use to read.

Then we must "drill", search deeper and look for a personal reading before the fi st drawing.

The fi st of so many.

Like Bradbury's says, concerning the writing and the need of having to work hard, the illustration requires many drawings and countless attempts. What is the best approach?

The illustrator need to meet the designer at this stage if they aren't the same person to define, together, the "intervention zone" in order to deal with the relationship between the empty space, lettering and the edges of the available space. This should be a work of interaction and mutual exchanges within the same framework.

Illustration should create a new speech that allows the opening of other ways to the reader. This is a task that is not easy and requires a relationship, often tense, between the drawing and the text. To draw literally from what is written or "fly" o an approach that tells to the reader: you have under your eyes two different narratives that match but each one follows different tracks. Do you want to follow yours? To be the author of a third story? It is up to you.

Otherwise we will close doors and windows and by the end of the day illustration turns to a mere decoration of contents.

That is why it is so difficult to speak of illustration as a whole when we are in the presence of so many ways and so many texts that are so different.

"There are perhaps no days of our childhood we lived so fully as those we believe we left without having lived them, those we spent with a favorite book." Marcel Proust

Illustration has the power to connect you to your childhood. Or to speak about matters of everyday life.

To children but also to adults.

To illustrate Lewis Carroll's Alice or to illustrate the arab springand the young freedom fighters, or sports and science, history or Severything.

This is its strength but also its weakness. 
$2^{\text {nd }}$ International Conference Art, Illustration and Visual Culture in Infant and Primary Education
${ }^{\circ}$ Congresso Internaciona

de Arte, Ilustração e Cultura Visual

na Educação Infantil e Primária

Too much illustration can kill illustration because it often creates the pressure of a mainstream taste that may prevent the assertion of emergent discourses.

We may take the example of contemporary illustration agencies.

On one hand scouts of those agencies can find ork that, otherwise, would not reach the hands of the illustrator. On the other they have the power of creating "trends" out of which is often complex a personal statement of alternative proposals. Always underpaid.

Although this is a reality closely linked to information and the illustration of news features and it is important that the illustration for children will be free of such constraints.

Illustration has a strong and considerable force for its synthesis which helps to decode hermetic contents specially in this peculiar period we live in when the ability to concentrate and to read is about to die facing new media interactions, permanent movement and an unbearable noise.

It is a form of writing. Especially for children. It is the link of a happy transition between two worlds without necessarily having a break between them. It is a starting point and at the same time a bridge.

Creates a memory mostly indelible. It is an enduring memory. We do not want to leave it because it call us into our childhood, the beginning of our life.

"Nothing fi es a thing so intensely in the memory as the wish to forget it." Montaigne

That is why our memories are so different even though they are often anchored in the same illustrations.

To forget memories can be a form of oblivion and the illustration is there as a friend that never leaves.

We all have memories. Not only about illustrations but all that goes with them.

We see the remakes and new models sold by the market and we prefer always the originals. Look the Tintin example in spite of the fabulous Spielberg's recent movie.

We realize, now adults, their enormous cognitive force and we are even ready to "forget" the suspected pro-Nazi affil tions of Georges Remi - aka Hergé - the latent racism of "Tintin in the Congo" or the primary anti-communism of "Tintin in the Land of the Soviets" to look with emotion the unique stories and his fantastic "clear line" drawing.

Pure and permanent delight from page 1 to page 62 . Yes, because all the Tintin books have 62 pages!

Separated is the author of its creation.

But Hergé is recent.

We should revisit Tenniel, Browne, Doré and Daumier, Rockwell, Bordallo among others not to speak of modern and contemporary authors.

And we have so many and excellent illustrators everywhere and specially in Portugal.

Please cherish and do not forget them and their work.

"The distinction between the past, present and future is only a stubbornly persistent illusion." Albert Einstein

Every time we think or speak about the future we make amazing mistakes. It is a classic.

Let's avoid it then and let us try to work on mere assumptions.

Will the illustration evolve, or not, in this or that direction, creating new spaces, new dialogues and new poetics?

Will illustration no longer be done by hand - with a pencil, paintbrush, mouse or other tool moving to a brave new world where it could be "dictated" to a computer that performs our "orders". And if so will the drawing have a unique trace that is ours? And last but not least: is that important? 
de Arte, llustração e Cultura Visual

na Educação Infantil e Primária

Illustrators will adapt to the new discoveries and trends, as they always have, and, finall , do what they do so well: create.

Others will born already in this new world and it is important that they know very well how illustration traveled for a better until today to understand this evolution even if it is an illusion as Einstein tells us.

And what about the new mind maps and needs both of the illustrator and the reader?

The new storytelling will dematerialise their heroes, as it did in the past, like in the Japanese "manga"? What will be the role of violence and non-violence, environment, love and hope in a near future? Will those new illustrators understand the big story of the book from its early childhood to our days in a variety of supports - from paper to multi-touch, or other - for teens and adults, men and women of so different cultures and backgrounds?

We will have, instead of the actual 2 and 3D paradigms, a new 3D holographic spectrum with a completely new framework.

Illustration will face these challenges and will keep their intimate secrets with his readers as always did.

For Klee, with whom we began this journey, a point was a line that had gone for a walk.

Illustration, such as drawing, continue this journey, this never ending story, that always had a tremendous capacity to surprise us.

Traveling together because they can not live without each other. Together.

Because, of course, they are two of a kind.

\section{Henrique Cayatte}

Designer

University of Aveiro

Department of Communication and Art

Invited Assistant Professor 